\title{
What Determines the Credibility of the Central Bank of Israel in the Public Eye?*
}

\author{
Zeev Kril, David Leiser, and Avia Spivak \\ Ben Gurion University of the Negev
}

\begin{abstract}
In line with the rational expectations approach, economists emphasize transparency as a key factor for central banks' credibility. In this paper, a psychological approach yields different results: trust in the banks' policy is associated with the professionalism and independence of the bank and not with its transparency. It is a subtle difference: transparency is indeed a positive factor in the overall perception of the bank as trustworthy, but a statistical analysis shows that not all aspects of perception are relevant to trust in the bank's credibility in its inflationary policy.
\end{abstract}

JEL Codes: E58.

\section{Introduction}

Central banks cannot function in the absence of trust. Other branches of the government need trust too, but for the central bank it is crucial because trust has replaced the gold standard as the anchor of the world's monetary system. Following the demise of the Bretton Woods monetary regime, price stability is dependent upon the fiscal and monetary policy of the government, and the trust in those policies experienced by economic agents. In essence, it consists of the belief that the central bank is in control of the money supply, and that current monetary policy is adequate for

*We wish to thank Stephen Lea, Ro'iZultan, Bradley Ruffle, IAREP 2012 conference participants, and the Bank of Israel seminar participants for their helpful comments; and Anne Dubitzky and Kineret Kimhi for editorial help. Corresponding author: Avia Spivak, Department of Economics, Ben Gurion University, POB 653 Beer Sheva 84105, Israel. E-mail: avia@exchange.bgu.ac.il; Tel: $+972-54-4979225$. 
maintaining price stability 11 The recent proliferation of inflationtargeting regimes (Fouejieu and Roger 2013, Salle 2013) formalizes this trust through the attempt to influence the public inflationary expectations. The central bank has a formal or informal inflation target, most often around 2 percent per year, which attempts to anchor inflationary expectations.

Israel is a fine example of the success of inflation targeting: it managed to complete its disinflation process, starting at a hyperinflation rate of 445 percent in 1984, going through around 10 percent in the 1990s, and settling at its current inflation rate, which is in the low one-digit range. This success hinges upon the ability of the Bank of Israel to persuade the public that it adheres to its inflation target-between 1 and 3 percent per year - even though it often missed it 2 The anchoring of inflationary expectations is important per se, but it also allows the Bank to pursue anti-cyclical monetary policy: easing the money supply in times of economic slowdown. If the inflationary expectations are firmly anchored, the public does not interpret this move as a signal that inflation is returning, but rather as a real increase in the money supply and credit.

The acquired reputation of the central bank is a solution to the well-known "time-inconsistency problem" introduced by Prescott and Kydland: policymakers sometimes have an incentive to say one thing, but later do something else. One solution is for policymakers to develop a reputation for credibility and recognize that the long-term benefits of having a reputation for reliability exceed the short-run costs involved (Gomme 2006, Rogoff 1985).

Central bank credibility means price and wage setters will be more willing to exercise restraint if they believe the central bank is firmly committed to price stability (Krugman 2012). A high level of central bank credibility should lead to various economic advantages such as less costly disinflation-when the bank operates to lower inflation rates. It also prevents random shocks in prices and causes less fluctuation in inflationary expectations (Herrendorf and

\footnotetext{
${ }^{1}$ The OECD targeted trust in government as one of the subjects the organization wants to address in the aftermath of the current crisis, and it stressed the need to use tools from behavioral economics and psychology in this endeavor (OECD 2013).

${ }^{2}$ It is easy to gauge inflationary expectations in Israel as the difference between the interest rates on indexed and non-indexed government bonds.
} 
Lockwood 1997). Further, it enables the bank to make tactical changes in monetary policy without inducing fear in the financial markets. Lastly, even when the bank acts as lender of last resort or has to protect the local currency against speculators, the required policies won't necessarily lead to an increase in inflationary expectations, provided the bank enjoys a good reputation (Blinder 2000).

The above explains why efforts to attain and measure credibility are valuable. Notions like "credibility" — which, like most abstract concepts, are somewhat nebulous - must be defined precisely (Gomme 2006). Very often, credibility is measured by the difference between medium-/long-term public expectations regarding the bank's target and the target itself. Since public expectations about inflation constitute one of the key factors that determine actual inflation, the interest of the bank in this measure is clear. However, this measure is not a clean indicator of the basic credibility of the bank, the basis of the inflation-targeting regime. This is because inflationary expectations are a combination of the analysis of economic conditions together with the bank's powers and intentions. The measure which we develop in this paper is designed to gauge the latter only: how people view the ability and intentions of the bank.

We measured the credibility of the Bank of Israel by asking respondents how much confidence they have in the Bank's inflationary forecasts and also growth forecasts. We then combined these measures with perceptions of laypeople regarding the Bank, in order to determine what creates the Bank's credibility in the public eye.

The Bank of Israel's forecasts are made by the Bank's research department and its reports are published twice a year (Bank of Israel 2011). We chose this item because the Bank places much emphasis on these forecasts. It makes an effort to convince the public that its forecasts are objective and reliable, by detailing the procedure and the models underlying them. The forecasts are one of the tools that the Bank uses to convince the public that it is serious about its commitment to control inflation and to confine it within its target. While our measure of credibility is tightly linked to the inflation forecasts, it focuses on the confidence that the public has in the Bank's forecasting abilities, rather than in the outcome of its actions.

In an attempt to determine what factors affect a central bank's credibility, Blinder (2000) asked eighty-four central bank governors 
to rate the variables that make a central bank credible. "A history of living up to its word" and "independence from the political system" were found to be the most important factors (with no significant difference between them). A history of fighting inflation and transparency followed, in terms of importance (again, no significant difference between them), while low fiscal deficit, clear rules, and incentives to the bank's governor ranked last.

However, the governors' views do not necessarily represent those of the public at large. Indeed, this would be unlikely, as their position and experience endows them with a thoroughly atypical perspective. It is important to study the attitudes of laypeople, since they are those who by their economic behavior affect prices through expectations. Expectations regarding future prices affect today's purchases, which in turn affect today's prices, and this means that laypeople's expectations regarding prices are critical for the control of inflation (Gaffeo and Canzian 2011). Due to the complexity of causal relations in economics, it seems doubtful that the public grasps the nature of the central banks' actions and their purpose, and indeed, it may well fail to understand the very function of central banks. As Arthur (2005) stresses, economics is inherently difficult. Professional arguments relating to the central bank's credibility are exceedingly technical. If the public tries to evaluate its activity, it must perforce impose some simpler structure and rely on heuristics (Leiser and Aroch 2009) to decide how much credence to give to the bank's pronouncements.

Much is already known about what may happen when comprehension is challenged. Psychologists distinguish two modes of mental functioning, and these map onto two qualities of trust: trust based on either cognitive-rational processes or on automatic-affective ones (Castelfranchi and Falcone 2010; Gangl et al. 2012). The differentiation in cognitive-rational and automatic-affective trust echoes a distinction made in various theoretical and empirical contexts, such as the dual models of Darlow and Sloman (2010); Epstein and Pacini (1999), or the Elaboration Likelihood Model (Petty and Cacioppo 1986) and the Heuristic Systematic Model (Chen and Chaiken 1999), both of which describe persuasion and attitude change.

We draw on Castelfranchi and Falcone's (2010) conceptualization of trust, and differentiate between reason-based and implicit trust. Reason-based trust represents the result of a rational argumentative 
decision (Castelfranchi and Falcone 2010). For our purposes, we will focus on the two main factors affecting the decision. The trustor evaluates the other's competence and willingness regarding the successful achievement of a specific goal. Competence means that the other is perceived as being capable of successfully achieving a certain goal. Willingness results from the assessment of the other's motivation, intention, and persistence to achieve a specific goal. The rational evaluation of these components combined with the costs, benefits, and dangers involved determine the degree of reason-based trust.

Reason-based trust therefore corresponds to trust definitions assuming a rational agent who trusts the other if it can be expected that he will forgo opportunistic goals (Coleman 1994). As we noted above, this is precisely what the reputation of a central bank relies on to achieve its goal despite the "time-inconsistency problem." By contrast, implicit trust is defined as an automatic, unintentional, and unconscious reaction to stimuli (Castelfranchi and Falcone 2010). The automatic reaction originates from associative and conditioned learning processes and memory. It is related to social trust (Welch et al. 2005) and to affective trust, as conceptualized by Jones (1996). Both qualities of trust - reason-based trust and implicit trust - are relevant to the perception of the central bank. One purpose of this study is to evaluate the relative importance of the two sets of processes (the reason-based and the implicit factors) in the evaluation of the central bank's credibility.

\section{Method}

Using social networks, e-mails, forums, and content sites, we publicized an online questionnaire that contained three sets of questions: (i) demographics; (ii) questions measuring the judged credibility in the economic predictions of the Bank of Israel, as compared with other major economic institutions; and (iii) questions regarding the respondents' assessment of the Bank's performance.

Data collection was concentrated in the period between May 16 and July 14, 2011. During this period, the most prominent global economic features were the continued decline in global markets and further deterioration of the European debt crisis. Meanwhile, Israel's economy experienced continued growth, leading to the strengthening of the shekel (the local currency) against the U.S. dollar, as well as 
a continued rise in housing prices. The inflation rate (twelve months ending in July 2011) was 4.1 percent, higher than the upper limit of the inflation target (3 percent), while inflationary expectations derived from markets stood at 2.9 percent (Bank of Israel interest rate press release, July 2011).

\subsection{Materials}

Our online questionnaire consisted of four sections and was constructed in a way that its average time of completion would not exceed eight to nine minutes. Therefore, the number of questions was kept small. Its sections were as follows: In the first, an overview of the task was given to participants and it was emphasized that filling in the questionnaire was voluntary; respondents could leave the questionnaire at any stage and information given by them would strictly be kept in confidence. The second section collected sociodemographic information.

In the third section, our operational goal was the extent to which our survey respondents believed that the Bank's forecasts will materialize. Each respondent rated, on a nine-point scale (ranging from $1=$ "Definitely not" to $9=$ "Definitely"), the level of trust they give to the forecasts on inflation and economic growth of the central bank. We then compared them with the forecasts of five major economic institutions which we used as reference. For each institution, we used the indicator it is mostly identified with, in the same way that central banks are associated with inflation and growth forecasts. The five institutions are (i) Bank Hapoalim, the largest commercial bank in Israel, (ii) the international investment bank Goldman-Sachs, (iii) the Israeli Ministry of Finance, (iv) the Manufacturers' Association of Israel, and (v) Teva, a global pharma company and the largest firm in Israel. To ensure that we measured trust in the institutions' forecasts, rather than forecasts about the current economic situation, all questions were formulated hypothetically, the time involved was left undefined, and the predicted values exceeded current estimates by 20 percent to 100 percent. The following will serve to illustrate the questions we asked:

Assume the Bank of Israel expects the CPI to rise in a particular year between 5 and 6 percent. Please rate on a scale of 1 to 
9, to what extent do you believe that the Bank's forecast will be realized and will the CPI will indeed fall in this range?

The last section measured respondents' perceptions regarding the Bank. Respondents rated, on a six-point scale $(1=$ "Not at all" to $6=$ "Very much"), the extent of their agreement with fifteen statements regarding the Bank of Israel. Some of the statements were formulated as positive, others as negative. Two additional statements were formulated as "semantic differential" scales - a method in which participants are asked to declare their positions regarding a phrase on a scale between two bipolar adjectives, as for example: "The Bank of Israel is a political/professional institution." In general, all statements were relevant to the role and reputation of the central bank. Questions were adapted from statements used by Vigoda (2000) and Vigoda and Mizrahi (2010), who studied public trust in the Israeli public sector, to which we added questions about topics not covered by them and required for our study. The order of the questions in each section was modified randomly for each participant, to control for order effects. Table 1 presents all the statements dealing with preferences, functions, and performance of the Bank as a fair, transparent, independent, professional, and trustworthy institution.

\subsection{Participants}

When publicizing the questionnaire, we endeavored to reach all socioeconomic levels of the Israeli population, with a wide range of age, professions, and educational level. The distribution procedure yielded 1,083 responses, of which 50 percent (542) completed the questionnaire. We excluded partially completed questionnaires and questionnaires completed by respondents with an academic degree in economics, leaving us with laypeople only. We further excluded forms bereft of variance (e.g., all answers were rated 6) as indicating respondents who were only interested in glancing at the questions or to reach the questionnaire's end. The final sample consists of 481 respondents (mean age $=39.9, \mathrm{SD}=13.7)$, of which 249 were female and 232 male, who had no (288) or little (193) formal training in economics. Among the respondents, 98 had no college education, 274 were undergraduates, and 168 were studying for or had completed their graduate studies. When asked to rate their socioeconomic 


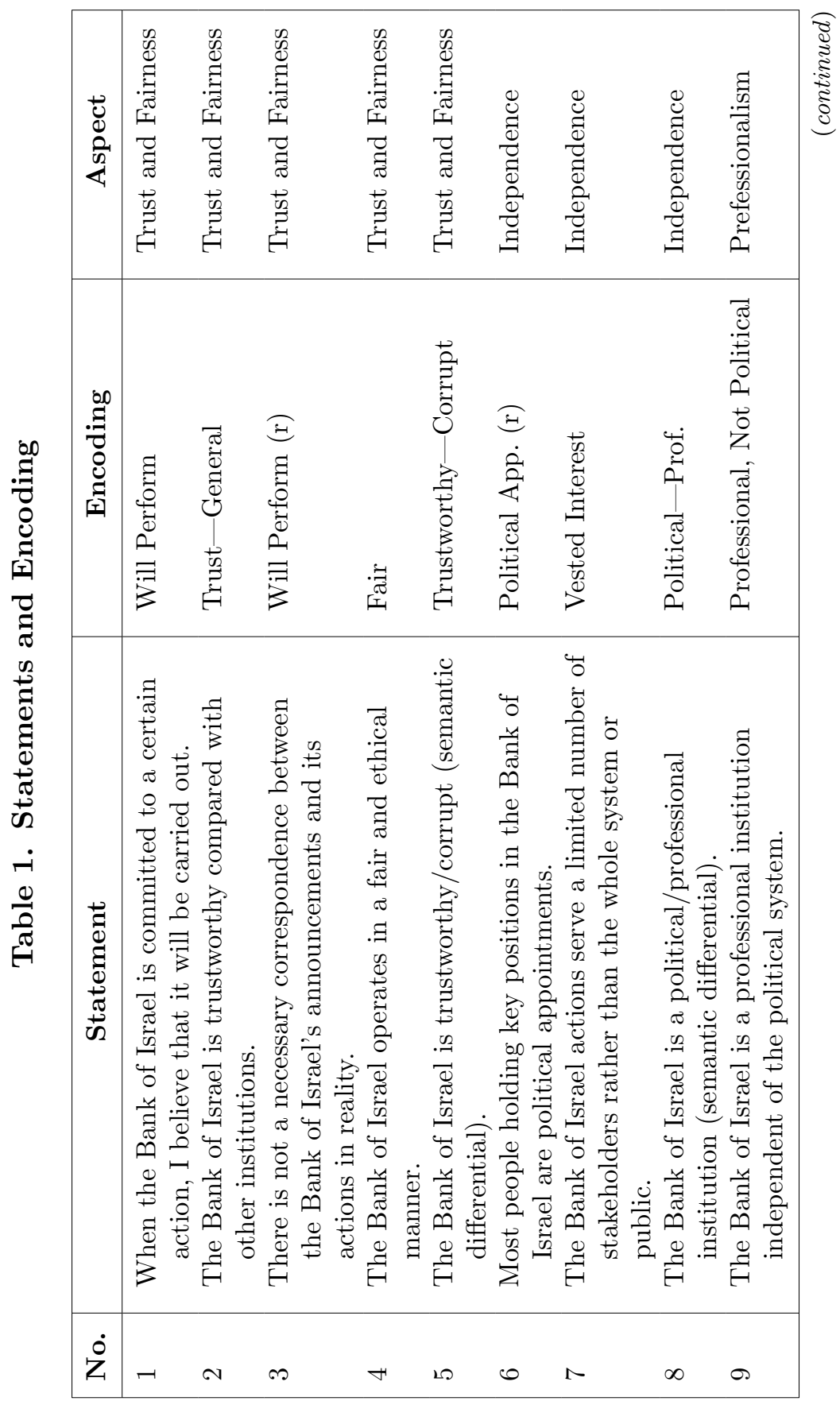


Vol. 12 No. 1 What Determines the Credibility of the Central Bank 75

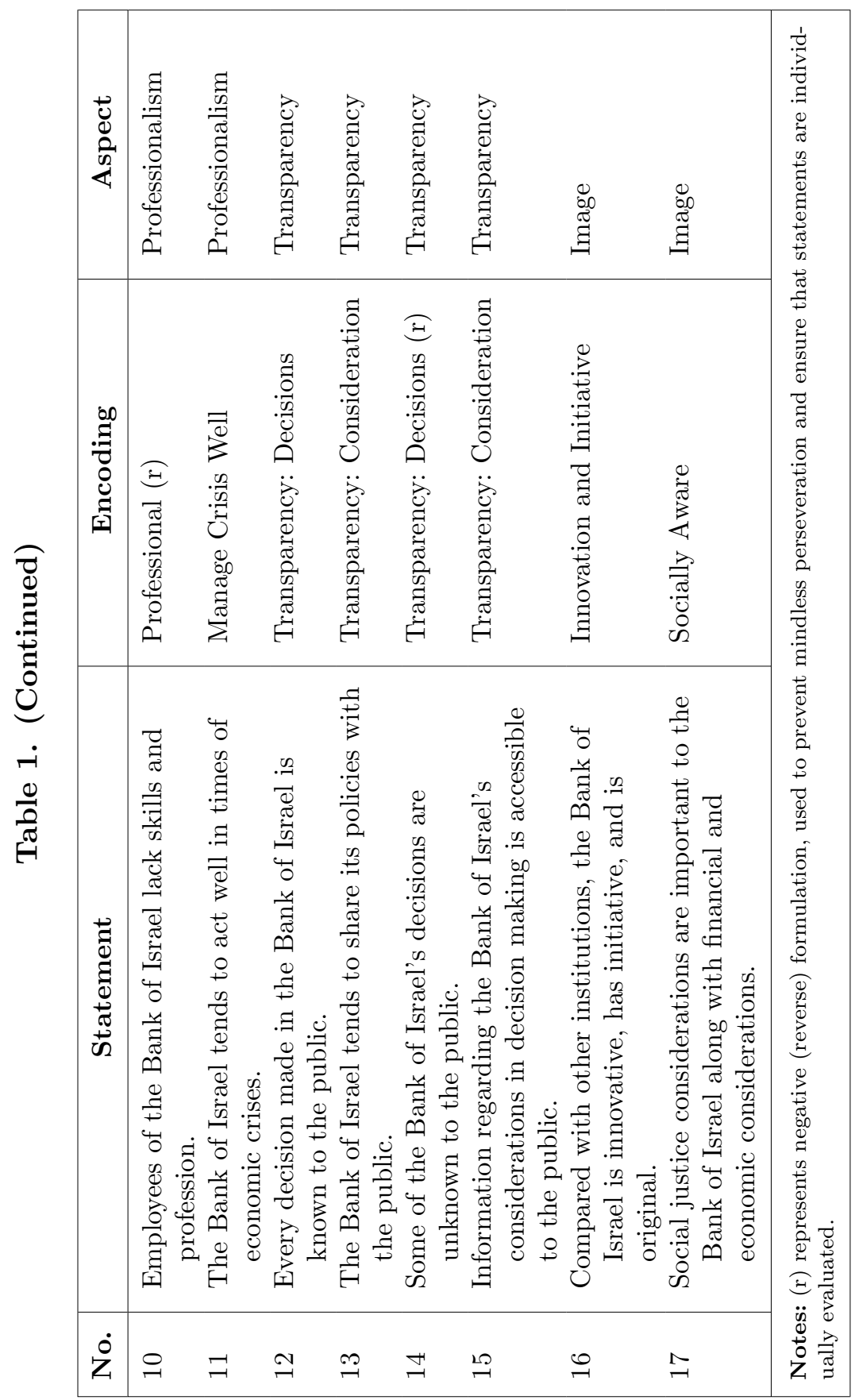


status, 74 respondents perceived themselves as having lower-thanaverage income, 288 as having average income, and 180 as having above-average income. In terms of occupational status, 327 were salaried employees and 92 were independently employed. Regarding the level of exposure to the economic media, 111 reported "rarely exposed," 247 reported "sometimes," and 122 reported "often." As for the nature of their employment, we dichotomized the responses: 109 were classified as managers (either independently employed or supervising at least four employees), and all other 372 participants were classified as employees. Lastly, the mean answer to the question "to what extent do you feel that the Bank of Israel's actions impact your life" was $6.17(\mathrm{SD}=1.91)$ on a scale of 1 to $9(1=$ "Very low", $9=$ "Very high impact").

\section{Results}

Analysis of the questionnaires was conducted in a straightforward manner. First, we examined the level of trust in the Bank's predictions compared with that in other economic institutions. Next, we examined perceptions regarding the Bank's performance. Lastly, we combined these two parts, using a regression and mediation analysis, to examine the correlation between perceptions regarding the Bank of Israel and the level of trust in its predictions.

\subsection{Measuring Trust in the Bank's Predictions}

Overall, the mean trust given to predictions of all the economic institutions about which we asked was $5.31(\mathrm{SD}=1.66)$ on a scale of 1 to $9(1=$ "Definitely not" to $9=$ "Definitely"). This average is slightly higher than the center of the scale. An ANOVA analysis with repeated measurements showed that not all forecasts are equally trusted: $\mathrm{F}(6,2880)=82.89, \mathrm{p}<0.0001, \eta^{2}=.14$. The highest level of trust was in the Bank of Israel's CPI forecast $(\mathrm{M}=5.98$, $\mathrm{SD}=1.50)$, followed by that of Teva's revenue forecast $(\mathrm{M}=5.80$, $\mathrm{SD}=1.58)$, the Bank of Israel's economic growth forecast $(\mathrm{M}=5.66$, $\mathrm{SD}=1.59)$, the Ministry of Finance's government deficit forecast $(\mathrm{M}=5.18, \mathrm{SD}=1.60)$, Bank Hapoalim's interest rate forecast $(\mathrm{M}=5.14, \mathrm{SD}=1.63)$, the Manufacturers' Association's hiring growth rate forecast $(\mathrm{M}=5.00, \mathrm{SD}=1.54)$, and last, the Goldman 
Sachs U.S. dollar exchange rate forecast $(\mathrm{M}=4.43, \mathrm{SD}=1.65)$. Planned contrasts indicated that the level of trust in the Bank of Israel's inflation and growth forecasts is higher than trust in other economic institutions' forecasts regarding the indicators with which they are associated. The difference between the Bank of Israel and the other institutions pooled is statistically significant: $\mathrm{F}(1480)=$ $190.11, \mathrm{p}<.01, \mathrm{MS}=345.96$. The average level of trust in the Bank of Israel's forecasts (inflation and growth) was 5.82, 95 percent confidence interval (CI) $[5.71,5.93]$, while the average level of trust given in other institutions was 5.11, 95 percent CI [5.02, 5.20]. The average difference between the level of trust in the central bank and in other institutions, to which we refer hereafter as the central bank credibility advantage (CBCA), is $+0.71,95$ percent CI $[0.6,0.8]$. We will use these averages as we proceed in the analysis, since averages of mixed indices are a more reliable way to reach conclusions.

\subsection{Aspects of Perceptions Regarding the Bank of Israel}

We extracted the main aspects of public perceptions by conducting principal component analysis (PCA) - a method for dimensionality reduction aimed at extracting the fundamental structure of a set of variables. We ran PCA on the scores on the thirteen statements regarding the Bank of Israel (see table 2). Results were tested by a variety of methods, with and without rotation. We present here the findings with the simplest orthogonal rotation-Varimax raw method. This method maximizes the variances of the squared raw factor loadings across variables for each factor, thus isolating distinct factors. We excluded those statements which directly deal with perceiving the Bank as trustworthy (statements 1-3 and 5) for reasons that will become clear presently. This procedure yielded three underlying factor 3 that jointly account for 59.43 percent of the total variance:

(i) Professionalism: Professionalism accounts for 24 percent of the variance and regroups four statements, presented in bold in table 2. Underlying these is the perception of the central bank as a professional rather than a political institution, an aspect crucial to the central bank's independence.

\footnotetext{
${ }^{3}$ We did not include factors with eigenvalue $<1$.
} 
Table 2. PCA Results

\begin{tabular}{|c|c|c|c|}
\hline & $\begin{array}{c}\text { Factor } 1 \\
\text { Professionalism }\end{array}$ & $\begin{array}{c}\text { Factor } 2 \\
\text { Transparency }\end{array}$ & $\begin{array}{c}\text { Factor } 3 \\
\text { Social Awareness } \\
\text { and Innovation }\end{array}$ \\
\hline Professional (r) & -0.73 & -0.07 & -0.04 \\
\hline Political App. (r) & -0.70 & -0.14 & -0.18 \\
\hline Vested Interest & -0.76 & -0.17 & -0.13 \\
\hline $\begin{array}{l}\text { Political- } \\
\quad \text { Professional }\end{array}$ & 0.71 & 0.27 & 0.31 \\
\hline $\begin{array}{l}\text { Transparency: } \\
\text { Decisions }\end{array}$ & 0.06 & 0.70 & 0.33 \\
\hline $\begin{array}{l}\text { Transparency: } \\
\text { Decisions (r) }\end{array}$ & -0.28 & -0.81 & 0.08 \\
\hline $\begin{array}{l}\text { Innovation and } \\
\text { Initiative }\end{array}$ & 0.35 & 0.01 & 0.70 \\
\hline Socially Aware & 0.09 & 0.14 & 0.72 \\
\hline $\begin{array}{l}\text { Transparency: } \\
\text { Considerations }\end{array}$ & 0.05 & 0.54 & 0.48 \\
\hline $\begin{array}{l}\text { Manage Crisis } \\
\text { Well }\end{array}$ & 0.51 & -0.01 & 0.52 \\
\hline Fair & 0.57 & 0.11 & 0.55 \\
\hline $\begin{array}{l}\text { Transparency: } \\
\text { Considerations }\end{array}$ & 0.13 & 0.47 & 0.58 \\
\hline $\begin{array}{l}\text { Professional } \\
\text { (Not Political) }\end{array}$ & 0.50 & 0.28 & 0.51 \\
\hline $\begin{array}{l}\text { Prop. Total } \\
\text { Variance }\end{array}$ & 0.24 & 0.14 & 0.21 \\
\hline
\end{tabular}

(ii) Transparency: Transparency accounts for 14 percent of the variance and regroups two statements. The common underlying notion is the transparency of the Bank of Israel - of its decisions, as opposed to its considerations in making those decisions.

(iii) Social Awareness and Innovation: This factor accounts for 21 percent of the variance and also regroups two statements, relating to a positive image of the central bank as innovative and socially aware, without reference to its official role in the economy. 
Table 3. Correlation Matrix of the Three Indices

\begin{tabular}{|l|c|c|c|}
\hline & $\begin{array}{c}\text { Social Awareness } \\
\text { and Innovation }\end{array}$ & Professionalism & Transparency \\
\hline $\begin{array}{c}\text { Social Awareness } \\
\text { and Innovation } \\
\begin{array}{l}\text { Professionalism } \\
\text { Transparency }\end{array}\end{array}$ - $^{0.505^{* *}}$ & - & \\
\hline Notes: ${ }^{* *}$ represents p-value $<0.05$. & $0.379^{* *}$ & - \\
\hline
\end{tabular}

\subsection{The Relationship between Perceptions and Credibility}

In order to estimate the relative influence of these factors on shaping the public perception of the Bank, statements loaded with 0.7 and above were grouped into three new indices (Professionalism, Transparency, and Social Awareness and Innovation) by averaging the scores of the component questions. These indices do correlate with each other (see table 3). This may be expected from the so-called halo effect, a type of cognitive bias in which one's overall impression of a person or an institution influences in return how one evaluates individual components related to that impression. In addition, we devised another index, General Trust, by averaging the scores of three statements in the questionnaire that directly deal with the Bank as trustworthy (statements 1, 2, and 5).

To find out how the relevant indices are related and affect belief in predictions of the central bank, we proceeded in several steps. First, we regressed General Trust on the three indices in a multiple regression analysis. All three indices were found to affect the general perception of the Bank as trustworthy: $\mathrm{F}(4,476)=147.38, \mathrm{R}^{2}$ adj. $=0.55$ (see table 4$)$.

We then examined the impact of these three indices on credibility of the Bank's predictions, by running two additional multiple regressions. In the first regression the dependent variable was simply the degree of trust in the central bank's predictions. We regressed the dependent variable on the three indices, along with an additional variable - Influence - which represents the answer to the question: "To what extent do you feel that the Bank of Israel's actions impact your life?" $\mathrm{F}(4,476)=16.894, \mathrm{R}^{2}$ adjusted $=0.117$. However, using this approach may be misleading. We are interested 
Table 4. Effect of the Three Indices on General Trust

\begin{tabular}{|c|c|c|c|c|c|}
\hline & Beta & $\begin{array}{l}\text { S.E. of } \\
\text { Beta }\end{array}$ & B & $\begin{array}{l}\text { S.E. } \\
\text { of } B\end{array}$ & p-level \\
\hline $\mathrm{C}$ & & & 0.94 & 0.15 & 0.00 \\
\hline Transparency*** & 0.18 & 0.03 & 0.18 & 0.03 & 0.00 \\
\hline Influence* & 0.06 & 0.03 & 0.02 & 0.01 & 0.06 \\
\hline $\begin{array}{l}\text { Social Awareness } \\
\text { and Innovation*** }\end{array}$ & 0.26 & 0.04 & 0.26 & 0.04 & 0.00 \\
\hline Professionalism*** & 0.47 & 0.04 & 0.47 & 0.04 & 0.00 \\
\hline
\end{tabular}

in elucidating specifically to what extent attributing those traits to the central bank impacts trust in its predictions, over and beyond trust in economic institutions in general. To achieve that focus, we repeated the analysis, substituting as predicted variable Central Bank Credibility Advantage (CBCA, see above): $\mathrm{F}(4,476)=4.585$, $\mathrm{R}^{2}$ adjusted $=0.029$.

The patterns of the two analyses are very similar, and only two of the predictors proved significant: there is a positive relationship between perceiving the Bank as a professional institution (competent and apolitical) and as influential, and the credibility of its predictions (see table 5) 4 Strikingly, Transparency and Social Awareness and Innovation were found to have no effect on the level of trust in the central bank's predictions.

Finally, we investigated whether General Trust mediates between the effect of specific perceptions regarding the Bank and trust in its predictions. A mediation model attempts to identify what underlies an observed relationship between predictor and predicted variable via the inclusion of a third explanatory variable, known as a mediator variable, by positing a causal chain in which the predictor variable affects the mediator that, in turn, affects the predicted variable. To test this, we examined several regression results, as recommended by Baron and Kenny (1986):

\footnotetext{
${ }^{4}$ The higher unstandardized coefficient in the first regression stems from the high correlation between trust in the Bank of Israel's predictions and those of the other institutions.
} 
Table 5. Predicted Trust in Central Bank's Predictions

\begin{tabular}{|c|c|c|c|c|c|}
\hline & Beta & $\begin{array}{l}\text { S.E. of } \\
\text { Beta }\end{array}$ & B & $\begin{array}{l}\text { S.E. } \\
\text { of B }\end{array}$ & p-level \\
\hline \multicolumn{6}{|c|}{ A. Predicted Absolute Trust } \\
\hline $\mathrm{C}$ & & & 3.17 & 0.36 & 0.00 \\
\hline Transparency & 0.02 & 0.05 & 0.04 & 0.08 & 0.64 \\
\hline Influence $* * *$ & 0.22 & 0.04 & 0.16 & 0.03 & 0.00 \\
\hline $\begin{array}{l}\text { Social Awareness } \\
\text { and Innovation }\end{array}$ & 0.01 & 0.05 & 0.01 & 0.08 & 0.89 \\
\hline Professionalism $* * *$ & 0.24 & 0.05 & 0.40 & 0.09 & 0.00 \\
\hline \multicolumn{6}{|c|}{ B. Predicted Unique Trust } \\
\hline $\mathrm{C}$ & & & -0.34 & 0.32 & 0.28 \\
\hline Transparency & -0.05 & 0.05 & -0.07 & 0.07 & 0.30 \\
\hline Influence $* * *$ & 0.13 & 0.05 & 0.08 & 0.03 & 0.00 \\
\hline $\begin{array}{l}\text { Social Awareness } \\
\text { and Innovation }\end{array}$ & 0.02 & 0.05 & 0.02 & 0.07 & 0.74 \\
\hline Professionalism** & 0.13 & 0.05 & 0.19 & 0.08 & 0.01 \\
\hline
\end{tabular}

- We regressed (see above) General Trust on the three perceptions factors (Professionalism, Transparency, and Social Awareness and Innovation) and showed that all three affect it (see table 4).

- The General Trust variable significantly affects credibility (for the level of trust in the Bank's predictions; see table 6): $\mathrm{F}(1,479)=65.103, \mathrm{R}^{2}$ adj. $=0.118$; and $\mathrm{F}(1,479)=15.635$, $\mathrm{R}^{2}$ adj. $=0.030$.

- We compared the outcomes of two regressions first with General Trust as an explanatory variable in addition to Professionalism and Influence (see table 7), and then without it (see table 5). When General Trust is added to the equation $\mathrm{F}(5,475)=19165, \mathrm{R}^{2}$ adj. $=0.159 ; \mathrm{F}(5475)=5.23, \mathrm{R}^{2}$ adj. $=0.042$, Professionalism no longer has a significant effect on credibility (see table 7 ). 


\section{Table 6. Effect of Perceived General Trust in Central Bank's Predictions}

\begin{tabular}{|l|c|c|c|c|c|}
\hline & Beta & $\begin{array}{c}\text { S.E. of } \\
\text { Beta }\end{array}$ & B & $\begin{array}{c}\text { S.E. } \\
\text { of B }\end{array}$ & p-level \\
\hline \multicolumn{6}{|c|}{ A. Effect on Absolute Credibility of Central Bank's Predictions } \\
\hline C & & & 3.33 & 0.31 & 0.00 \\
General Trust*** & 0.35 & 0.04 & 0.58 & 0.07 & 0.00 \\
\hline \multicolumn{7}{|c|}{ B. Effect on Unique Credit Given in Central Bank's Predictions } \\
\hline C & 0.18 & 0.04 & 0.25 & 0.06 & 0.00 \\
General Trust*** & 0.01 ; Beta are the standardized coefficients, B the \\
\hline \\
Notes: *** represents p-value < \\
unstandardized ones.
\end{tabular}

These findings are schematized in figure 1: General Trust mediates the effect of Professionalism on the credibility of the central bank's predictions, whereas Influence is an independent factor. The other two factors, Transparency and Social Awareness and Innovation, are not involved.

The above method is one that many researchers use, but it has come under criticism.5 A statistically more satisfactory approach is to calculate the indirect effect and test its significance directly, as introduced by Sobel (1982). According to the Sobel product of coefficients approach, the indirect effect may be calculated by multiplying two regression coefficients. For this, we examined the two predictor variables in turn by conducting a regression analysis with (i) the absolute degree of trust in the central bank's predictions, and (ii) $C B C A$ as the dependent variables and General Trust as the mediator. The two components found significant in our regression analysis above (Influence and Professionalism) served separately as independent variables. For Professionalism, the expected mediation emerged with a sizable indirect effect of 0.33 and 0.15 (Sobel $\mathrm{Z}_{\mathrm{a}}=4.94$ and $\left.\mathrm{Z}_{\mathrm{b}}=2.57, \mathrm{p}<.05\right)$. That value of 0.15 represents the difference

\footnotetext{
${ }^{5}$ One issue is that the Baron and Kenny approach does not specifically test the significance of the indirect pathway. Furthermore, the approach tends to miss some true mediation effects, leading to type 2 errors (MacKinnon, Fairchild, and Fritz 2007).
} 


\section{Table 7. Predicted Trust in Central Bank's Predictions, All Indices}

\begin{tabular}{|c|c|c|c|c|c|}
\hline & Beta & $\begin{array}{l}\text { S.E. of } \\
\text { Beta }\end{array}$ & B & $\begin{array}{l}\text { S.E. } \\
\text { of } B\end{array}$ & p-level \\
\hline \multicolumn{6}{|c|}{ A. Predicted Absolute Trust, All Indices } \\
\hline $\mathrm{C}$ & & & 2.68 & 0.36 & 0.00 \\
\hline Trust in General*** & 0.31 & 0.06 & 0.52 & 0.10 & 0.00 \\
\hline Influence ${ }^{* * *}$ & 0.20 & 0.04 & 0.14 & 0.03 & 0.00 \\
\hline $\begin{array}{l}\text { Social Awareness } \\
\text { and Innovation }\end{array}$ & -0.07 & 0.05 & -0.12 & 0.09 & 0.15 \\
\hline Professionalism & 0.09 & 0.06 & 0.15 & 0.10 & 0.11 \\
\hline Transparency & -0.03 & 0.05 & -0.06 & 0.08 & 0.47 \\
\hline \multicolumn{6}{|c|}{ B. Predicted Trust, All Indices } \\
\hline $\mathrm{C}$ & & & -0.58 & 0.33 & 0.07 \\
\hline Trust in General*** & 0.18 & 0.07 & 0.26 & 0.09 & 0.01 \\
\hline Influence ${ }^{* *}$ & 0.12 & 0.05 & 0.07 & 0.03 & 0.01 \\
\hline $\begin{array}{l}\text { Social Awareness } \\
\text { and Innovation }\end{array}$ & -0.03 & 0.06 & -0.04 & 0.08 & 0.58 \\
\hline Professionalism & 0.05 & 0.06 & 0.07 & 0.09 & 0.45 \\
\hline Transparency* & -0.08 & 0.05 & -0.12 & 0.07 & 0.09 \\
\hline
\end{tabular}

between the effect of Professionalism on the level of trust in the Bank's predictions (0.19) and the remaining direct effect (0.04) after introducing the mediator into the equation. In other words, most of the effect of Professionalism is mediated. For the Influence variable, the mediation contributes a negligible effect of 0.01 (Sobel $\mathrm{Z}_{\mathrm{a}}=2.50$ and $\left.\mathrm{Z}_{\mathrm{b}}=2.27, \mathrm{p}<.05\right)$. Table 8 summarizes the mediation analysis using Sobel's approach.

In sum, only the effect of Professionalism on credibility $(C B C A)$ is mediated by General Trust. Influence affects credibility $(C B C A)$ but is unmediated. The other two perception factors, Social Awareness and Innovation and Transparency, while they do affect General Trust, have no effect on credibility $(C B C A)$.

Conceptually, the meaning of these findings may be explicated with reference to the two dimensions of trust presented in the 


\section{Figure 1. General Trust as a Mediating Factor}

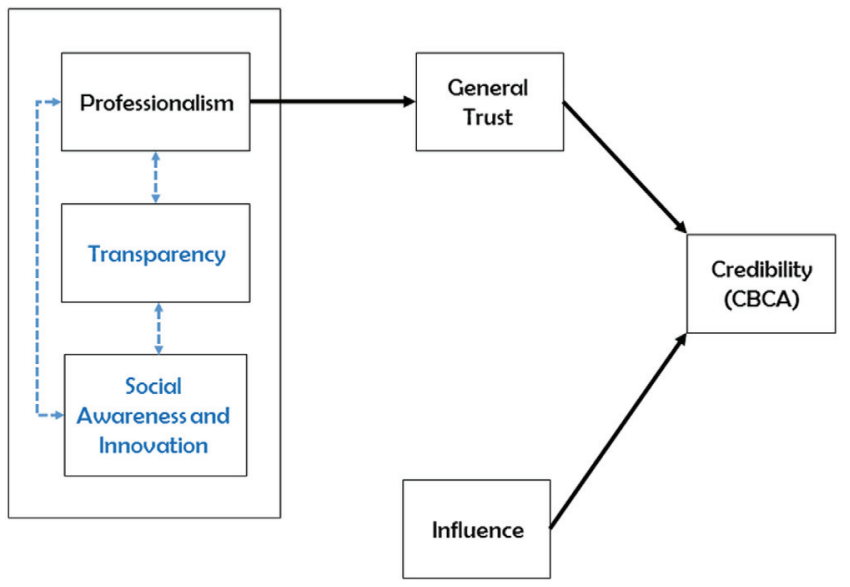

introduction (Castelfranchi and Falcone 2010): reason-based and implicit trust. As mentioned, the halo effect yields correlations between Professionalism, Social Awareness and Innovation, and Transparency; they all contribute to a positive feeling and General Trust in the Bank. This is a manifestation of implicit trust, an associative and unanalyzed reaction to the Bank. However, when it comes time to decide whether to trust the central bank's predictions, the respondents evinced reason-based trust and showed that they were able to go beyond that "warm glow" and identify the properties that count. These include Professionalism and Influence but neither Social Awareness and Innovation nor Transparency.

\subsection{Who Perceived the Bank as Trustworthy?}

We now turn to examine how the characteristics of the respondentssuch as their social and economic status, background training in economics, and exposure to the economic media-affect lay opinion of the Bank. We used data-mining methods for answering this question. The first step was to classify respondents in accordance with the patterns of their responses on the three perception indices and the General Trust variable (see above). The classification was made by K-means clustering (StatSoft, Inc. 2013), an algorithm that divides groups into clusters by maximizing the difference between 
Vol. 12 No. 1 What Determines the Credibility of the Central Bank 85
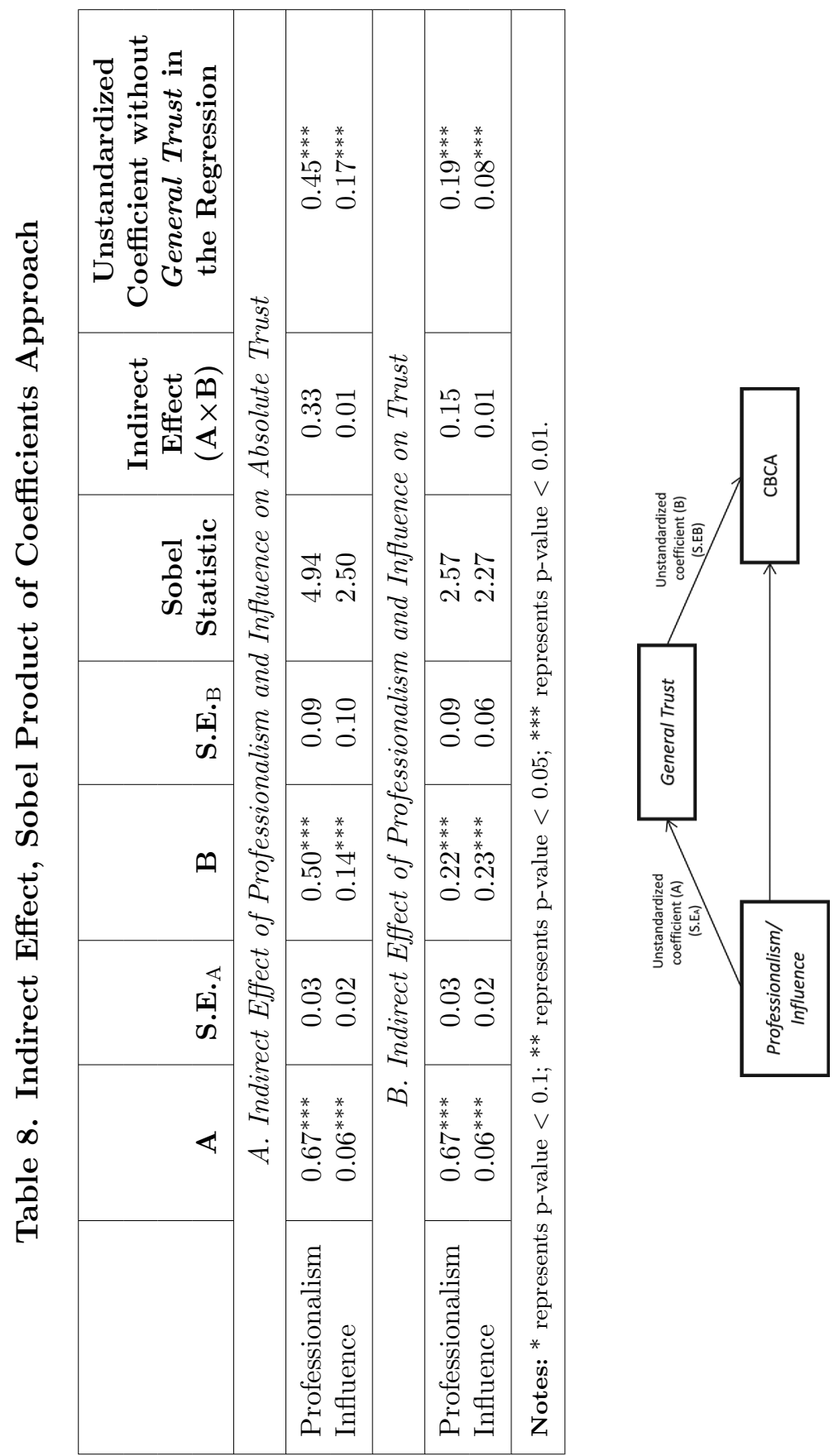


\section{Figure 2. A Comparison of Answering Patterns according to Clusters Means}

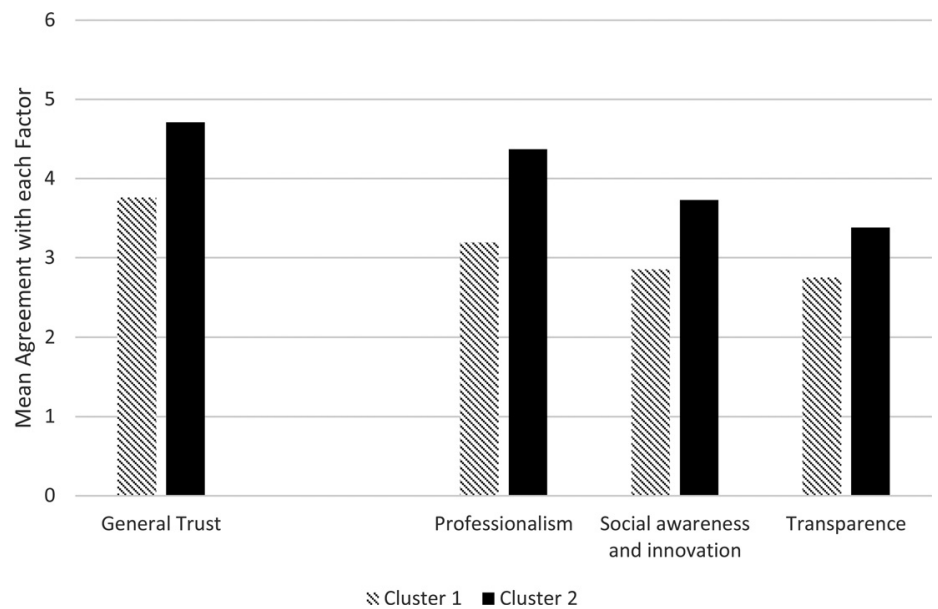

clusters and minimizing the difference within each cluster. The difference between the clusters, as reflected in the patterns of respondents' answers, appears in figure 2. Respondents who were classified as cluster 1 (shaded) tend to identify the central bank as a political institution rather than a transparent, innovative, socially aware institution, and see it as less trustworthy. Conversely, respondents classified as cluster 2 (black) tend to identify the central bank as a generally trustworthy institution, independent from the political system, transparent, innovative, and socially aware.

Next, we examined how independent variables affect the likelihood of belonging to each cluster. To cope with this classification problem, we used chi-squared automatic interaction detection (CHAID, alpha to split < 0.1) - an algorithm used for constructing non-binary decision trees, which relies on the chi-square test to determine the best split at each step. The CHAID algorithm effectively yields many multi-way frequency tables and therefore is suitable for large data sets (StatSoft, Inc. 2013). Variables that the algorithm could use for the classification were socioeconomic status (self-reported), level of education, nature of employment, exposure to the economic media, and a background including some formal knowledge in economics. Of these, it was Exposure to Media and 
Figure 3. Importance of Factors Entered in the CHAID Analysis

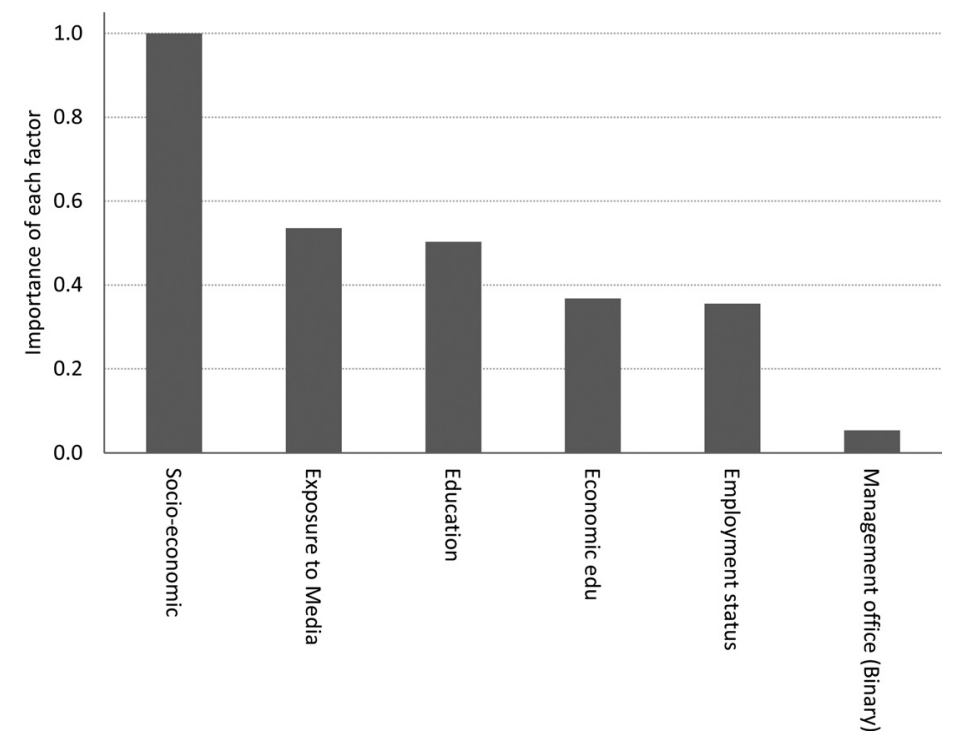

Socio-Economic Status (SES) that yielded the best classification (see figure 3). The classification results appear in figure 4. Individuals who reported themselves as unexposed to economic media and those with lower income have a less positive perception of the Bank of Israel. Respondents with high income who reported themselves as consistently exposed to economic media hold the most positive perception of the Bank.

\section{Discussion}

Trust in the central bank is an essential requirement for fulfilling its basic function. Our study shows that the Israeli public trusts its central bank more than other main economic institutions which were used as reference for the analysis. This is in line with previous findings: according to a longitudinal survey launched in 2001, trust in the Bank of Israel is consistently high as compared with other economic institutions. In 2010, for example, trust in the Bank was valued as 3.12 on a scale of 1 to 5 , while trust in the Ministry of 


\section{Figure 4. CHAID Tree: Successive Splits of the Overall Sample according to Cluster Membership}

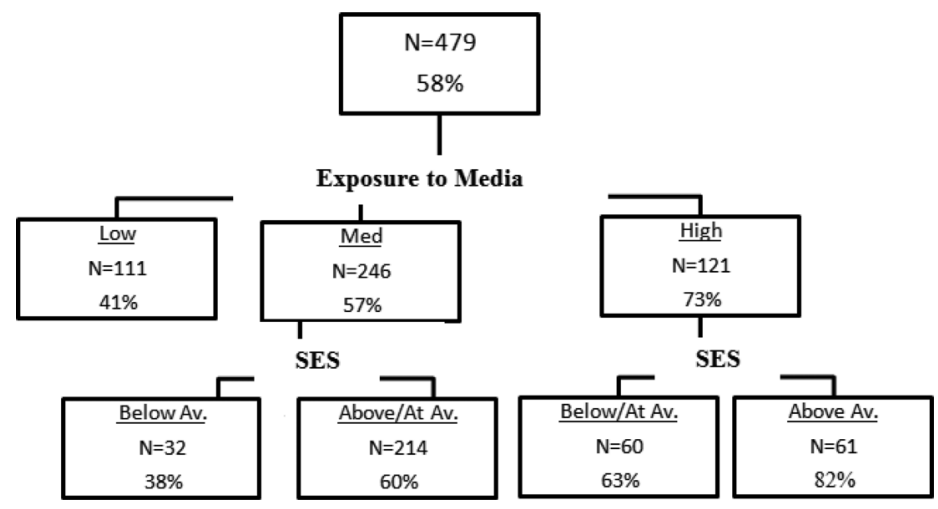

Notes: The figure represents the probability of belonging to cluster 1 . The main differences between the two clusters are income and the level of exposure to economic media channels: Individuals who are unexposed to economic media have a less positive perception of the bank of Israel-out of those (111), 46 (41 percent) belong to cluster 1 . Respondents with higher-than-average income, who are consistently exposed to economic media, perceive the bank as highly trustworthy - out of those (61), 50 (82 percent) belong to cluster 1 .

Finance was valued as 2.59 and trust in the tax authority and other Israeli banks was valued as 2.69 (Vigoda and Mizrahi 2010).

We endeavored to identify those people who have a more positive view of the central bank. Respondents cluster in two groups: one cluster tends to view the central bank as a generally trustworthy institution, able to function independently from the political system, transparent, innovative, and socially aware, compared with the second cluster of respondents. Of the demographic factors we collected, two were the most predictive of a positive view: exposure to economic media and socioeconomic status (SES). Belonging to a higher SES and being regularly exposed to economic information in the media were independently associated with a positive view of the central bank. The influence of the media is consistent with Lamla and Lein (2008), who found that the media have power to change inflationary expectations. Media reports on the Bank of Israel tend to be positive, and so it is unsurprising that the media effect in our survey is positive. In 2010, the Bank of Israel used image analysis to 
measure changes in the Bank's reputation (Bank of Israel, internal unpublished report). Sixty-five percent of the press reports had a positive tone, as did 56 percent of the online reports, whereas only 15 percent of all reports were negative.

Factor analysis of the public perception of the bank yielded three main factors: Professionalism (including freedom from political meddling), Transparency, and Social Awareness and Innovation. All three factors predict general trustworthiness. However, trustworthiness and credibility of inflationary forecasts are not the same. To analyze the latter, we computed a new variable, $C B C A$, representing the extent to which a respondent believes that the predictions of the central bank are credible, beyond the credibility attributed to those of several other institutions. To establish robustness, we also used the absolute value of the trust in the central bank.

The findings are striking and at variance with those of Blinder (2000), who polled central banks' governors. Of the three aspects of perception, Professionalism predicts the credibility advantage attributed to the central bank $(C B C A)$, while perceived Transparency and Social Awareness and Innovation do not. The extent to which respondents judge that the central bank impacts their life (Influence) also enhances its credibility. Predictions of the central bank are considered credible to the extent that the Bank is perceived as an independent institution and as powerful, influential, and relevant. This interpretation is further strengthened by our mediation analysis: trustworthiness (General Trust) mediates only the effect of Professionalism on credibility $(C B C A)$. Influence also affects credibility $(C B C A)$, but trustworthiness does not mediate this effect. The other two perception factors, Social Awareness and Innovation and Transparency, while they affect trustworthiness and have a relatively high correlation with Professionalism, do not affect the extra (unique) credit given to the central bank.

High correlations between the perception aspects, and between perception aspects and General Trust, suggest that the public perception of the central bank involves a halo effect. The halo effect is a cognitive bias in which judgments are influenced by overall impressions without differentiating the details. This is a manifestation of implicit trust (Castelfranchi and Falcone 2010), an associative and unanalyzed reaction to the Bank. In contrast, expectations concerning the credibility of the central bank predictions involve 
reason-based trust. The pertinent factors are differentiated and identified: Professionalism and Influence. For the general public, neither the Bank's image regarding Social Awareness and Innovation, nor Transparency are deemed relevant. Social Awareness and Innovation represents notions of the Bank as civic minded and respectful of citizens, notions that do not necessarily relate to the Bank's purposes and relate even less to its ability to carry them out. Openness and success are not necessarily related in the eyes of the public, especially in Israel. Many Israelis take pride in the secret operations of special military units whose legendary discretion serves as a marker of their seriousness and modesty. While central banks increase the level of transparency in decision-making processes (Geraats 2009; Salle 2013), our findings indicate that transparency, much stressed by central bankers, is not perceived by the general public as relevant to the Bank's ultimate success in achieving its goals.

The central bank seeks to manage private expectations in order to achieve a better stabilization of both inflation and economic activity. For the general public, only the core meaning of transparency (informing the public of its goals and predictions; Salle 2013) is relevant. The public takes in that information and uses heuristics to decide whether to credit it. Those heuristics do not include the Bank's reasoning and motivations, as the public is incapable of understanding them. Instead, it judges whether to believe that the goals will be achieved and the predictions will materialize on the basis of its appraisal of the Bank's "willingness and competence" (Castelfranchi and Falcone 2010) - whether it is genuinely willing and able to achieve them.

The situation is of course very different when it comes to economic experts. To them, openness about the basis for the Bank's pronouncements is not a potential heuristic marker of a well-behaved institution: it constitutes a source of information. The opportunity to pore over the considerations underlying the decisions and predictions of the central bank enables experts to evaluate them professionally and to conclude rationally whether to accept them.

\section{References}

Arthur, W. B. 2005. "Cognition: The Black Box of Economics." In Perspectives on Adaptation in Natural and Artificial Systems, ed. 
L. Booker, S. Forrest, M. Mitchell, and R. Riolo, 291 (chapter 14). Oxford University Press.

Bank of Israel. 2011. "Monetary Policy Report (Inflation Report), January-March 2011." (May). Available at www.bankisrael. gov.il.

Baron, R. M., and D. A. Kenny. 1986. "The Moderator-Mediator Variable Distinction in Social Psychological Research: Conceptual, Strategic, and Statistical Considerations." Journal of Personality and Social Psychology 51 (6): 1173-82.

Blinder, A. S. 2000. "Central-Bank Credibility: Why Do We Care? How Do We Build It?" American Economic Review 90 (5): 142131.

Castelfranchi, C., and R. Falcone. 2010. Trust Theory: A Sociocognitive and Computational Model. Wiley Series in Agent Technology, Vol. 18. John Wiley \& Sons.

Chen, S., and S. Chaiken. 1999. "The Heuristic-Systematic Model in Its Broader Context." In Dual-Process Theories in Social Psychology, ed. S. Chaiken and Y. Trope, 73-96. The Guilford Press.

Coleman, J. S. 1994. Foundations of Social Theory. Harvard University Press.

Darlow, A. L., and S. A. Sloman. 2010. "Two Systems of Reasoning: Architecture and Relation to Emotion." Wiley Interdisciplinary Reviews: Cognitive Science 1 (3): 382-92.

Epstein, S., and R. Pacini. 1999. "Some Basic Issues Regarding DualProcess Theories from the Perspective of Cognitive-Experiential Self-Theory." In Dual-Process Theories in Social Psychology, ed. S. Chaiken and Y. Trope, 462-82 (chapter 23). The Guilford Press.

Fouejieu, A., and S. Roger. 2013. Inflation Targeting and Country Risk: An Empirical Investigation. IMF Working Paper No. 13/21. Gaffeo, E., and G. Canzian. 2011. "The Psychology of Inflation, Monetary Policy and Macroeconomic Instability. Journal of Socio-Economics 40 (5): 660-70.

Gangl, K., B. Kastlunger, E. Kirchler, and M. Voracek. 2012. "Confidence in the Economy in Times of Crisis: Social Representations of Experts and Laypeople." Journal of Socio-Economics 41 (5): 603-14.

Geraats, P. M. 2009. "Trends in Monetary Policy Transparency." International Finance 12 (2): 235-68. 
Gomme, P. 2006. "Central Bank Credibility." Economic Commentary (Aug 1).

Herrendorf, B., and B. Lockwood. 1997. "Rogoff's 'Conservative' Central Banker Restored." Journal of Money, Credit and Banking 29 (4): 476-95.

Jones, K. 1996. "Trust as an Affective Attitude." Ethics 107 (1): $4-25$.

Krugman, P. 2012. "The Credibility Fixation." Blog Entry, May 9. The Conscience of a Liberal.

Lamla, M., and S. Lein. 2008. "The Role of Media for Consumers' Inflation Expectation Formation." Working Paper No. 08-201, KOF Swiss Economic Institute.

Leiser, D., and R. Aroch. 2009. "Lay Understanding of Macroeconomic Causation: The Good-Begets-Good Heuristic." Applied Psychology 58 (3): 370-84.

MacKinnon, D. P., A. J. Fairchild, and M. S. Fritz. 2007. "Mediation Analysis." Annual Review of Psychology 58: 593-614.

OECD (Organisation for Economic Cooperation and Development). 2013. "New Approach to Economic Challenges (NAEC)." Scoping Paper, OECD.

Petty, R. E., and J. T. Cacioppo. 1986. "The Elaboration Likelihood Model of Persuasion." In Communication and Persuasion, 1-24. New York: Springer.

Rogoff, K. 1985. "The Optimal Degree of Commitment to an Intermediate Monetary Target." Quarterly Journal of Economics 100 (4): 1169-89.

Salle, I. 2013. "Ciblage de l'inflation, transparence et anticipationsune revue de la littérature récente." Revue d'économie politique 123 (5): $697-736$.

Sobel, M. E. 1982. "Asymptotic Confidence Intervals for Indirect Effects in Structural Equation Models." Sociological Methodology 13: $290-312$.

StatSoft, Inc. 2013. Electronic Statistics Textbook. Tulsa, OK: StatSoft. Available at http://www.statsoft.com/textbook/.

Vigoda, E. 2000. "Are You Being Served? The Responsiveness of Public Administration to Citizens' Demands: An Empirical Examination in Israel." Public Administration 78 (1): 165-91.

Vigoda, E., and S. Mizrahi. 2010. "The Performance of the Israeli Public Sector: A Citizens Survey and National Assessment." 
Vol. 12 No. 1 What Determines the Credibility of the Central Bank 93

Working Paper No. 10, Academy for Quality Government (in Hebrew).

Welch, M. R., R. E. Rivera, B. P. Conway, J. Yonkoski, P. M. Lupton, and R. Giancola. 2005. "Determinants and Consequences of Social Trust." Sociological Inquiry 75 (4): 453-73. 